\title{
High Fluoride Concentration Toothpastes for Children and Adolescents
}

\author{
Iain A. Pretty \\ Dental Health Unit, School of Dentistry, University of Manchester, Manchester, UK
}

\section{Key Words}

Adolescents · Caries · Children · Effectiveness · High fluoride dentifrices

\begin{abstract}
The purpose of this review is to present the available evidence to support the use of dentifrices with high $(>1,500$ ppm) concentrations of fluoride to help in the prevention and treatment of caries in high-risk children and adolescents. Recent evidence from high-quality systematic reviews supports the dose-response relationship between caries prevention and fluoride levels, and there is good evidence from randomised clinical trials to support the use of high fluoride dentifrices. Such products are typically prescribed oral pharmaceuticals that require thorough risk assessment by the clinician and restricting use in those less than 6 years old to cases where the risk of severe morbidity caused by caries is greater than that of aesthetically objectionable fluorosis and which should mitigate the risk of fluorosis. Further research is required on the use of population- or communitybased interventions using such products and currently, the evidence for dentifrices containing more than $2,900 \mathrm{ppm}$ is weaker than for those containing 2,800 ppm or less.
\end{abstract}

(c) 2016 The Author(s)

Published by S. Karger AG, Basel

\section{KARGER}

E-Mail karger@karger.com www.karger.com/cre

\section{C) 2016 The Author(s) \\ Published by S. Karger AG, Basel 0008-6568/16/0507-0009\$39.50/0}

This article is licensed under the Creative Commons AttributionNonCommercial-NoDerivatives 4.0 International License (CC BYNC-ND) (http://www.karger.com/Services/OpenAccessLicense). Usage and distribution for commercial purposes as well as any distribution of modified material requires written permission.
It is now accepted that caries is a dynamic process of de- and re-mineralisation and, when the balance of factors favours de-mineralisation, then caries will progress [Pretty and Ellwood, 2013]. There are opportunities during the progression of the carious lesion to arrest and reverse the process, although these are largely limited to the non-cavitated stages [Featherstone, 2004]. The use of systems to detect early carious lesions, and hence those suitable for preventive rather than surgical intervention, have been adopted in light of this [Gomez et al., 2013].

Since the late 1960s, following the introduction of widespread use of fluoridated dentifrices, there has been a substantial decrease in caries within Western populations [Kassebaum et al., 2015]. The biological presentation of caries has changed during this time, with the majority of new lesions occurring on occlusal rather than smooth surfaces [Biesbrock et al., 2001]. This biological change has been accompanied by an epidemiological shift from a ubiquitous disease to one that is increasingly restricted to sub-population groups, especially those in lower social economic groups and those with special needs [McGrady et al., 2012]. This 'ghettoisation' of caries is of concern to those with public health responsibilities as such groups are often hard to reach, have a low utilisation of dental services and face a range of other 
Table 1. Determinants of high caries risk in children and adolescents [Davies and Davies, 2008]

\begin{tabular}{|c|c|}
\hline Factor & Feature \\
\hline Diet & Characterized by high sugar intake \\
\hline Current disease & Previous caries or high DT/DS \\
\hline Saliva & Low flow \\
\hline Appliances & Orthodontic fixed appliances \\
\hline $\begin{array}{l}\text { Dental attendance } \\
\text { patterns }\end{array}$ & Infrequent, symptomatic attendance \\
\hline Restorations & Evidence of previous disease \\
\hline Socio-economic & Deprived communities \\
\hline Family & $\begin{array}{l}\text { Family and sibling history of caries and } \\
\text { poor attendance }\end{array}$ \\
\hline Medications & Sugared medications \\
\hline
\end{tabular}

DT/DS = Decayed teeth/decayed surfaces.

health care issues of concern [Schwendicke et al., 2015]. Table 1 provides some of the characteristics of these groups.

Children with caries also face considerable morbidity as a result of the disease, with many having extractions under general anaesthetic [Goodwin et al., 2015a]. Recent research has revealed that these children suffer from continued pain, sleepless nights and missed school. Such comorbidities further exacerbate the consequences of what is a preventable disease [Goodwin et al., 2015b]. In the UK, the most common reason for children to be admitted to hospital continues to be multiple tooth extraction under general anaesthetic [Goodwin et al., 2015a].

There is, therefore, a need to consider means by which caries in these groups can be addressed. While community-based water fluoridation is often advocated for such groups in many jurisdictions, this is not possible for logistical or political reasons. Therefore, in the absence of water fluoridation, do toothpastes with higher concentrations of fluoride than those traditionally accessed by consumers (1,000 through 1,450 ppm fluoride) offer additional therapeutic benefits for those children and adolescents at high risk of caries?

\section{The Fluoride Dose Response}

There is a well-established dose-response relationship between the concentration of fluoride present in dentifrices and caries prevention [Moller et al., 1968; Reed, 1973; Tavss et al., 2003] and the evidence to support the use of fluoridated toothpastes is described by Cochrane as unequivocal [Wong et al., 2011]. A recent Cochrane review examined the use of fluoride toothpastes containing up to 2,800 ppm and described a dose-response effect to this level but stated that this was not always statistically significant between individual concentrations. The review found that the highest probability of caries preventive benefits was found in those toothpastes containing greater fluoride concentrations [Walsh et al., 2010]. In previous comparisons with placebos, low concentrations (400-550 ppm) demonstrated no significant benefit (and hence should not be recommended for use), with those with 'standard' levels of fluoride having a median preventive fraction of $25 \%$ and those with the highest levels of fluoride $(2,800 \mathrm{ppm})$ a preventive fraction of $45 \%$. These findings were mirrored in an earlier review by Ammari et al. [2003] that considered differences between pastes with as low as 250 up to $1,055 \mathrm{ppm}$.

The Cochrane systematic review provides high-quality evidence based on 79 trials and 73,000 children that higher concentrations of fluoride confer additional benefit in the form of caries prevention [Walsh et al., 2010]. Given the extent of this review, and its recent publication, it is not appropriate to re-review the topic here. It is worth noting, however, that the majority of the contributing studies were examining the comparison of lower fluoride concentration pastes with standard products.

Consequently, it is worthwhile to consider some of the detail of the contributing studies (those with interventions over 1,500 ppm), as well as to consider the evidence for dentifrices with fluoride concentrations in excess of $2,800 \mathrm{ppm}$ (typically $5,000 \mathrm{ppm}$ ) that were not considered within the review.

A search was therefore conducted in the PubMed, Web of Science and Ovid MEDLINE databases using a modified version of the search criteria employed within the Cochrane systematic review [Walsh et al., 2010]. Modifications to fluoride level and study design were employed in order to obtain the widest possible literature base. The following studies, divided into fluoride levels, are described below.

\section{From 1,600 to $2,800 \mathrm{ppm}$}

Marks et al. [1992] reported a study examining the use of products containing 2,000 and 2,500 ppm fluoride compared with levels of 1,000 and 1,500 ppm. The study demonstrated that the DMFS increment in those subjects receiving the standard products was 4.23 . This dropped to 4.08 and 3.77 with increasing concentrations. This
10

Caries Res 2016;50(suppl 1):9-14 DOI: $10.1159 / 000442797$
Pretty 
Table 2. Summary of traditional caries studies examining dentifrices containing $>2,400 \mathrm{ppm}$ [Davies and Davies, 2008]

\begin{tabular}{|c|c|c|c|c|c|c|}
\hline Study & $\begin{array}{l}\text { Duration, } \\
\text { years }\end{array}$ & $\begin{array}{l}\text { Age at } \\
\text { baseline, } \\
\text { years }\end{array}$ & $\begin{array}{l}\text { Fluoride species } \\
\text { (concentration, ppm) }\end{array}$ & Increment & $\begin{array}{l}\text { Difference, } \\
\%\end{array}$ & $\begin{array}{l}\text { Signif- } \\
\text { icance }\end{array}$ \\
\hline Lu et al. [1985] & 3 & $7-15$ & $\begin{array}{l}\mathrm{NaF}(1,100) \\
\mathrm{NaF}(2,800)\end{array}$ & $\begin{array}{l}4.40 \\
3.88\end{array}$ & 12 & significant \\
\hline $\begin{array}{l}\text { Alexander and Ripa } \\
\text { [2000] }\end{array}$ & 3 & $10-13$ & $\begin{array}{l}\text { NaF/MFP }(1,000) \\
\text { NaF/MFP }(2,500)\end{array}$ & $\begin{array}{l}3.63 \\
3.67\end{array}$ & & n.s. \\
\hline Stephen et al. [1994] & 3 & $11-14$ & $\begin{array}{l}\operatorname{MFP}(1,000) \\
\operatorname{MFP}(1,500) \\
\operatorname{MFP}(2,500)\end{array}$ & $\begin{array}{l}6.83 \\
6.27 \\
5.56\end{array}$ & $\begin{array}{r}8 \\
18\end{array}$ & significant \\
\hline Marks et al. [1992] & 3 & $6-14$ & $\begin{array}{l}\operatorname{MFP}(1,000) \\
\operatorname{MFP}(2,500)\end{array}$ & $\begin{array}{l}4.23 \\
3.77\end{array}$ & 11 & significant \\
\hline Chesters et al. [2002] & 2 & $11-14$ & $\begin{array}{l}\operatorname{MFP}(1,000) \\
\operatorname{MFP}(2,500)\end{array}$ & $\begin{array}{l}5.47 \\
4.96\end{array}$ & 9 & significant \\
\hline $\begin{array}{l}\text { Stookey et al. [2004] } \\
\text { (examiner A) }\end{array}$ & 2 & $9-12$ & $\begin{array}{l}\mathrm{NaF}(1,100) \\
\mathrm{NaF}(2,800)\end{array}$ & $\begin{array}{l}6.27 \\
5.45\end{array}$ & 13 & significant \\
\hline $\begin{array}{l}\text { Stookey et al. [2004] } \\
\text { (examiner B) }\end{array}$ & 2 & $9-12$ & $\begin{array}{l}\mathrm{NaF}(1,100) \\
\operatorname{NaF}(2,800)\end{array}$ & $\begin{array}{l}4.95 \\
3.80\end{array}$ & 23 & significant \\
\hline
\end{tabular}

n.s. = Non-significant $\mathrm{NaF}=$ sodium fluoride; $\mathrm{MFP}=$ sodium monofluorphosphate.

study reports the clear directionality of the fluoride preventive effect - although, like the Cochrane review, statistical significance is not always observed between successive fluoride levels within clinical studies.

Biesbrock et al. [2001] presented data from a trial conducted in the 1980s. Children aged $6-15$ years $(n=5,439)$ were randomised into groups receiving dentifrices containing $1,100,1,700,2,200$ and $2,800 \mathrm{ppm}$ F. While the study ran for 3 years, data from the second and third year were confounded by a concurrent fluoride rinse programme. Results indicated that, after year 1, the 2,200 ppm (18.6\%) and 2,800 ppm (20.4\%) were statistically superior to $1,100 \mathrm{ppm}$ (control) when reductions in DMFS were considered. These results were similar to those found in studies by Lu et al. [1985] (2,800 ppm delivering statistically superior results to $1,100 \mathrm{ppm}$ over 3 years) and Stephen et al. [1994] (2,500 ppm delivering a statistically significant reduction in DMFS of $16-20 \%$ when compared with 1,000 ppm control).

A meta-analysis of 6 randomised clinical trials, examining fluoride concentrations of 1,700, 2,200 and 2,800 $\mathrm{ppm}$, found that the use of a paste containing 2,800 ppm resulted in 'statistically significant lower caries increment than the use of a dentifrice with 1,100 ppm. This result was noted after one, two, and three years of dentifrice use' [Bartizek et al., 2001]. The other concentrations demonstrated directional advantages over the 1,100 ppm control but these were not statistically significant.

Chesters et al. [2002] presented data examining the use of 1,000 versus $2,500 \mathrm{ppm}$ dentifrice in a 24 -month abbreviated study design. After 12 months, there was no difference in the groups, but by the second-year examination point, the 2,500 ppm group had 1.5 less decayed surfaces than the control group. A total of 2,011 children aged 13 years completed the study with a low level of drop out.

Stookey et al. [2004] describes a supervised brushing study comparing 2,800 ppm with $1,100 \mathrm{ppm}$ as part of a larger study investigating an experimental stannous fluoride product. As with previous works, statistically significant differences were found between the low, standard and 2,800 ppm groups. Children using the product containing 2,800 ppm experienced a $23.2 \%$ reduction (when attending more than $60 \%$ of supervised brushing sessions) compared with $1,100 \mathrm{ppm}$ when scored by one examiner, but a much smaller reduction by another - $13 \%$; both, however, were significantly superior to control. Table 2 presents a summary of the relevant studies. 


\section{From 2,800 to 5,000 ppm}

These concentrations are less well studied in the contemporary literature and did not form part of the Cochrane review or their meta-analysis. This is likely to be due to the heterogeneity of the studies, not least in their reported outcomes. Many of the studies were undertaken prior to the wide acceptance of good clinical practice and reporting standards such as CONSORT. In many cases, key components are missing from the published reports including, for example, loss to follow-up, randomisation methodology and the blinding of the study.

However, the totality of the evidence should be considered alongside the dose-response data previously described. The use of these products for the prevention and treatment of root caries is described by Ekstrand [2015] and not covered here again. It should also be noted that there are various methods of fluoride delivery and while the focus of this review is delivery via dentifrice, the traybased and gel studies have been included for completeness.

\section{Tray-Based Studies}

Englander et al. [1967] were the first to report a study examining the use of 5,000 ppm fluoride on coronal caries. This was a school-based clinical trial where custom-fitted trays were filled with either a gel containing $5,000 \mathrm{ppm}$ fluoride or inactive (placebo) ingredients daily for 21 months. The children were aged 11 through 14 years. The results were striking, with an overall reduction of $75 \%$ in DMFT in the intervention group compared with the control group. A further study replicated the main methodology of the earlier work but examined the impact of the presence of optimally fluoridated water supplies on the efficacy of high fluoride applications [Englander et al., 1971]. This is an important consideration in the USA where a large proportion of the population is served by fluoridated water supplies. The study reported that there was a significant improvement in the fluoridated group, proving additional benefit from the topical application of 5,000 ppm fluoride.

\section{Dentifrice Studies}

The following studies delivered 5,000 ppm fluoride via the traditional tooth-brushing method, using either dentifrice or gels.

A school-based program, utilising supervised brushing with a range of fluoride products (from 1,250 through to 5,000 ppm), was undertaken by Cutress et al. [1992].
Over a period of 26 months, 300 children in each intervention group received the brushing treatment and the final results support the previously described fluoride dose response. There was a clear relationship between the levels of fluoride in the products and caries preventive fraction, with the group taking products with 5,000 ppm fluoride reporting a $40-45 \%$ lower DMFT than those treated with the formulation containing 1,250 ppm fluoride. A total of 520 children fully participated in the study and were available for the final examination.

A further clinical study considering the efficacy of $5,000 \mathrm{ppm}$ fluoride on coronal caries is that by Nordstrom and Birkhed [2010]. This 2-year, randomised clinical trial compared the use of twice daily 1,450 versus $5,000 \mathrm{ppm}$ on adolescents aged $14-16$ years. The outcomes of the study reported that those using the product containing 5,000 ppm had significantly lower caries progression and lower incidence than those using the control paste. The study also examined the impact of compliance on the efficacy of high fluoride products in this particular age group. An independent review of this study stated that:

The 5,000 ppm toothpaste therefore appears to be an important vehicle for the treatment and prevention of caries in patients with a high caries risk. The data may indicate that 5,000 ppm toothpaste has a greater impact on individuals who do not use toothpaste regularly or do not brush twice a day [Duane, 2012].

While the majority of caries studies reporting the use of high concentration fluorides are 'conventional' in design and population, typically school based and in areas of high caries prevalence with outcomes reported as DMFT/DMFS, it should be noted that such products may be of use to other high-risk groups, including those who may be deemed 'high risk' as a result of the presence of fixed orthodontic appliances.

Research suggests that $72.9 \%$ of patients undergoing fixed orthodontic appliance treatment will develop at least 1 white spot lesion and many will develop cavitations. Given the largely aesthetic drivers for such elective treatment, the prevention of caries is essential [Richter et al., 2011].

Examining this group of patients, Alexander and Ripa [2000] reported that while the overall caries incidence in their orthodontic patients increased, those subjects that were allocated to the product containing 5,000 ppm fluoride had statistically significantly less caries than those in the control group (dentifrice with 1,000 ppm fluoride combined with an acidulated rinse).

Orthodontic populations were also the group of interest in a further study that assessed the twice-daily use
12

Caries Res 2016;50(suppl 1):9-14 DOI: $10.1159 / 000442797$
Pretty 
of a dentifrice containing 1,450 ppm fluoride versus 5,000 ppm [Sonesson et al., 2014]. A well-described study, with an average treatment duration of nearly 2 years and with over 200 subjects per group, the findings indicate that those subjects in the 5,000 ppm group had a statistically significant reduction in caries $(32 \%$ preventive fraction) compared to the $1,450 \mathrm{ppm}$ group. The study concluded that the use of high fluoride dentifrice products in those individuals undergoing fixed orthodontic treatment should be recommended [Sonesson et al., 2014].

In summary, the data surrounding the use of 5,000 ppm on younger patients is limited and is highly heterogeneous, being comprised of school-based studies, orthodontic studies and mixed delivery methodologies. There is, however, a consistency to the outcomes of the trials and this, combined with the biological plausibility and dose-response data, suggests that, for high-risk children and adolescents, such products have significant potential benefit. Figure 1 demonstrates a collective dose response from the described studies. This shows that, collectively, there is a $12.7 \%$ caries (DMFS) reduction per $1,000 \mathrm{ppm}$ $\mathrm{F}$ in toothpaste. Hence, $2,500-2,800 \mathrm{ppm}$ is $15-20 \%$ more effective than $1,000 \mathrm{ppm}$, and $5,000 \mathrm{ppm}$ is $30-40 \%$ more effective than 1,000 ppm.

\section{Fluorosis}

The use of higher fluoride products in children who are at risk of fluorosis (especially to their anterior teeth) must be carefully considered. This consideration should include the following:

1 the age and risk for fluorosis;

2 the status of water fluoridation in the community;

3 the use of any other fluoride-containing products;

4 the sources of any other non-therapeutic fluorides;

5 the risk of caries and its morbidities.

A Cochrane review stated that there was evidence to support that toothpastes with 1,000 ppm were associated with a higher risk of fluorosis when used in children aged 5-6 years [Wong et al., 2010]. They did, however, caveat this statement by indicating that the benefit of caries prevention may well outweigh the risk of aesthetically objectionable fluorosis [Wong et al., 2010]. It should also be noted that fluoride toothpastes above $1,450 \mathrm{ppm}$ are usually restricted to individuals aged over 6 years and, in most jurisdictions, are prescribed by health professionals following an appropriate risk assessment.

High Fluoride Toothpastes and Children

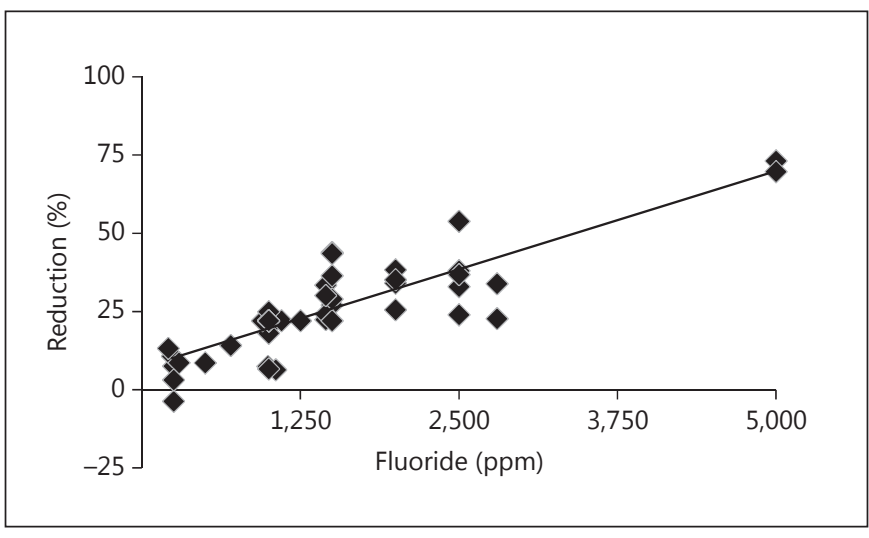

Fig. 1. Collective dose-response model from reported, published studies, showing the percentage of caries reduction compared with placebo.

\section{Research Challenges}

While the systematic reviews demonstrate good levels of support for dentifrices up to 2,800 ppm, there is a lack of contemporary clinical trial data (suitable for metaanalyses) regarding the use of 5,000 $\mathrm{ppm}$ in younger patients. This is important as $2,800 \mathrm{ppm}$ is available in only a small number of markets, leaving $5,000 \mathrm{ppm}$ as the only alternative to consumer brands.

Developing clinical trials of these therapeutics is difficult for a number of reasons. Notably, the target populations of high caries risk children are often reluctant to join clinical trials and regularly demonstrate poor compliance when they do. Additionally, due to the prescription requirements of these products, trials involving these drugs are subject to high levels of event reporting and regulatory surveillance. These factors result in complex and expensive trials. The current indications for high fluorides are the treatment of existing lesions and the prevention of new lesions developing - each requires a different clinical study with a different design.

\section{Conclusion}

There is a strong evidence base for the use of high fluoride toothpastes in groups at a greater risk of caries. The decision on the concentration of fluoride will be based on a number of factors, not least product availability in the prescriber's market. A thorough risk assessment of the patient is required prior to the prescription of such therapeutics and it is important to re-assess risk on a regular 
basis to determine whether the intervention is still required. The use of higher concentration fluoride products as community- or population-based interventions requires further research, but early studies on $5,000 \mathrm{ppm}$ suggest that they may have a role to play in addressing the burden of disease in hard-to-reach groups.

\section{Author Contributions}

Prof. Iain Pretty undertook the literature review and wrote the manuscript.

\section{Disclosure Statement}

Prof. Pretty is the co-director of the Dental Health Unit, which receives funding from the Colgate Palmolive Company.

\section{References}

Alexander SA, Ripa LW: Effects of self-applied topical fluoride preparations in orthodontic patients. Angle Orthod 2000;70:424-430.

Ammari AB, Bloch-Zupan A, Ashley PF: Systematic review of studies comparing the anti-caries efficacy of children's toothpaste containing $600 \mathrm{ppm}$ of fluoride or less with high fluoride toothpastes of 1,000 ppm or above. Caries Res 2003;37:85-92.

Bartizek RD, Gerlach RW, Faller RV, Jacobs SA, Bollmer BW, Biesbrock AR: Reduction in dental caries with four concentrations of sodium fluoride in a dentifrice: a meta-analysis evaluation. J Clin Dent 2001;12:57-62.

Biesbrock AR, Gerlach RW, Bollmer BW, Faller RV, Jacobs SA, Bartizek RD: Relative anti-caries efficacy of $1100,1700,2200$, and $2800 \mathrm{ppm}$ fluoride ion in a sodium fluoride dentifrice over 1 year. Community Dent Oral Epidemiol 2001;29:382-389.

Chesters RK, Pitts NB, Matuliene G, Kvedariene A, Huntington E, Bendinskaite R, Balciuniene I, Matheson JR, Nicholson JA, Gendvilyte A, Sabalaite R, Ramanauskiene J, Savage D, Mileriene J: An abbreviated caries clinical trial design validated over 24 months. J Dent Res 2002;81:637-640.

Cutress T, Howell PT, Finidori C, Abdullah F: Caries preventive effect of high fluoride and xylitol containing dentifrices. ASDC J Dent Child 1992;59:313-318.

Davies RM, Davies GM: High fluoride toothpastes: their potential role in a caries prevention programme. Dent Update 2008;35:320-323.

Duane B: 5,000 ppm F dentifrice for caries prevention in adolescents. Evid Based Dent 2012; 13:43-44.

Ekstrand K: High fluoride dentifrices for elderly and vulnerable adults. Does it work and if so, then why. Caries Res 2016;50(suppl 1):15-21.

Englander HR, Keyes PH, Gestwicki M, Sultz HA: Clinical anticaries effect of repeated topical sodium fluoride applications by mouthpieces. J Am Dent Assoc 1967;75:638-644.

Englander HR, Sherrill LT, Miller BG, Carlos JP, Mellberg JR, Senning RS: Incremental rates of dental caries after repeated topical sodium fluoride applications in children with lifelong consumption of fluoridated water. J Am Dent Assoc 1971;82:354-358.
Featherstone JD: The continuum of dental caries - evidence for a dynamic disease process. J Dent Res 2004;83:C39-C42.

Gomez J, Tellez M, Pretty IA, Ellwood RP, Ismail AI: Non-cavitated carious lesions detection methods: a systematic review. Community Dent Oral Epidemiol 2013;41:54-66.

Goodwin M, Sanders C, Davies G, Walsh T, Pretty IA: Issues arising following a referral and subsequent wait for extraction under general anaesthetic: impact on children. BMC Oral Health 2015a;15:3.

Goodwin M, Sanders C, Pretty IA: A study of the provision of hospital based dental general anaesthetic services for children in the northwest of England. Part 1. A comparison of service delivery between six hospitals. BMC Oral Health 2015b;15:50.

Kassebaum NJ, Bernabe E, Dahiya M, Bhandari B, Murray CJ, Marcenes W: Global burden of untreated caries: a systematic review and metaregression. J Dent Res 2015;94:650-658.

Lu KH, Yen DJ, Zacherl WA, Ruhlman CD, Sturzenberger OP, Lehnhoff RW: The effect of a fluoride dentifrice containing an anticalculus agent on dental caries in children. ASDC J Dent Child 1985;52:449-451.

Marks RG, D’Agostino R, Moorhead JE, Conti AJ, Cancro L: A fluoride dose-response evaluation in an anticaries clinical trial. J Dent Res 1992;71:1286-1291.

McGrady MG, Ellwood RP, Maguire A, Goodwin M, Boothman N, Pretty IA: The association between social deprivation and the prevalence and severity of dental caries and fluorosis in populations with and without water fluoridation. BMC Public Health 2012;12:1122.

Moller IJ, Holst JJ, Sorensen E: Caries reducing effect of a sodium monofluorophosphate dentifrice. Br Dent J 1968;124:209-213.

Nordstrom A, Birkhed D: Preventive effect of high-fluoride dentifrice $(5,000 \mathrm{ppm})$ in caries-active adolescents: a 2-year clinical trial. Caries Res 2010;44:323-331.
Pretty IA, Ellwood RP: The caries continuum: opportunities to detect, treat and monitor the remineralization of early caries lesions. J Dent 2013;41(suppl 2):S12-S21.

Reed MW: Clinical evaluation of three concentrations of sodium fluoride in dentifrices. J Am Dent Assoc 1973;87:1401-1403.

Richter AE, Arruda AO, Peters MC, Sohn W: Incidence of caries lesions among patients treated with comprehensive orthodontics. Am J Orthod Dentofacial Orthop 2011;139:657664.

Schwendicke F, Dorfer CE, Schlattmann P, Page LF, Thomson WM, Paris S: Socioeconomic inequality and caries: a systematic review and meta-analysis. J Dent Res 2015;94:10-18.

Sonesson M, Twetman S, Bondemark L: Effectiveness of high-fluoride toothpaste on enamel demineralization during orthodontic treatment - a multicenter randomized controlled trial. Eur J Orthod 2014;36:678-682.

Stephen KW, Chestnutt IG, Jacobson AP, McCall DR, Chesters RK, Huntington E, Schafer F: The effect of NaF and SMFP toothpastes on three-year caries increments in adolescents. Int Dent J 1994;44:287-295.

Stookey GK, Mau MS, Isaacs RL, Gonzalez-Gierbolini C, Bartizek RD, Biesbrock AR: The relative anticaries effectiveness of three fluoridecontaining dentifrices in Puerto Rico. Caries Res 2004;38:542-550.

Tavss EA, Mellberg JR, Joziak M, Gambogi RJ, Fisher SW: Relationship between dentifrice fluoride concentration and clinical caries reduction. Am J Dent 2003;16:369-374.

Walsh T, Worthington HV, Glenny AM, Appelbe $\mathrm{P}$, Marinho VC, Shi X: Fluoride toothpastes of different concentrations for preventing dental caries in children and adolescents. Cochrane Database Syst Rev 2010;1:CD007868.

Wong MC, Clarkson J, Glenny AM, Lo EC, Marinho VC, Tsang BW, Walsh T, Worthington HV: Cochrane reviews on the benefits/ risks of fluoride toothpastes. J Dent Res 2011; 90:573-579.

Wong MC, Glenny AM, Tsang BW, Lo EC, Worthington HV, Marinho VC: Topical fluoride as a cause of dental fluorosis in children. Cochrane Database Syst Rev 2010; 1:CD007693. 